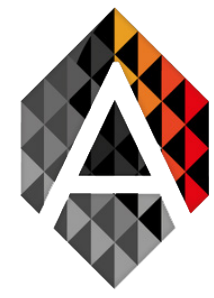

ADCAIJ: Advances in Distributed Computing and Artificial Intelligence Journal Regular Issue, Vol. 10 N. 1 (2021), 77-97

elSSN: 2255-2863

\title{
Comparative analysis of the management of the results of the modeling and the simulation of the evaluation of the thermal energy of the greenhouse by a fuzzy logic controller between a wet region and an arid region
}

\author{
*Malika Amari ${ }^{a}$, Didi Faouzi ${ }^{\text {, }}$ Benyoucef Khalili ${ }^{b}$, Foudil \\ Benzerafa $^{c}$ \& Mohammed Salim Hadjidj ${ }^{\mathrm{d}}$ \\ a Faculty of Technology, Department of common-core Technology,University Yahia \\ Fares of Medea, 26000 Algeria \\ b Laboratory of Petrochemical synthesis Faculty of hydrocarbons and chemistry \\ University Mohamed Bougara, Avenue de l'indépendance 35000 Boumerdes, Algeria \\ c Laboratoire de Recherche en Electrotechnique et en Automatique University of \\ Médéa Médéa, Algeria \\ d Unit of Research on Materials and Renewable Energies - URMER - Department of \\ Physics, Faculty of Sciences, Abou Bekr Belkaïd University, BP 119-13000-Tlemcen, \\ Algeria
}

amarimalika120@gmail.com didifouzi19@gmail.com, youcefk2005@yahoo.fr, benz.foudil@gmail.com, salimhadjidj14@gmail.com

\begin{tabular}{|c|c|}
\hline KEYWORD & ABSTRACT \\
\hline & \\
\hline & the regulation, monitoring and controls. Greenhouse growe \\
\hline balan & and attentive, facing this technological development. They ensure competitiveness \\
\hline Modeling & and optimize their investments / production cost which continues to grow. The \\
\hline Fuzzy Logic & application of artificial intelligence in the industry known for considerable \\
\hline Controller; & growth, which is not the case in the field of agricultural greenhouses, where \\
\hline Optimization; & enforcement remains timid. It is from this fact, we undertake research work in this \\
\hline Simulation; & area and conduct a simulation based on meteorological data through MATLAB \\
\hline Greenhouse \& & Simulink to finally analyze the thermal behavior greenhouse microclimate energy. \\
\hline Microclimate & $\begin{array}{l}\text { In this paper we present comparison of modeling and simulation management } \\
\text { of the greenhouse microclimate by fuzzy logic between a wetland (Dar El Beida } \\
\text { Algeria) and the other arid (Biskra Algeria). }\end{array}$ \\
\hline
\end{tabular}

Malika Amari, Didi Faouzi, Benyoucef Khalili, Foudil Benzerafa, Mohammed Salim Hadjidj

Comparative analysis of the management of the results of the modeling and the simulation of the evaluation of the thermal energy of the greenhouse...
ADCAIJ: Advances in Distributed Computing and Artificial Intelligence Journal Regular Issue, Vol. 10 N. 1 (2021), 77-97 eISSN: 2255-2863 - https://adcaij.usal.es Ediciones Universidad de Salamanca - CC BY-NC-ND 


\section{Introduction}

Agricultural greenhouse originally designed as a simple enclosure limited by a transparent wall (S.D. Dhamakale and S.B. Patil, 2011, Abdelhafid Hasni, B. Draoui, 2009), as is the case for conventional tunnel greenhouses and largely answered chapel in several countries including those of the Mediterranean basin (Campbell, Neil A. and Brad Williamson, 2006; Salgado and P. J. B. Cunha, and C. Couto, 1998).

They amplify certain characteristics of the surrounding environment, thus involving variations of internal energy and fairly significant heat loss due to the low inertia of the clamp system (N. Bibi-Triki and S. Bendimemerad, 2011; Abdelhafid Hasni and B. Draoui, 2008).

To maintain a microclimate suited to the demands of the protected culture (F. Bouaama and K. Lammari, 2008; Khelifa Lammari and F. Bouaama, 2012), energy intake and the introduction of new technologies and air conditioning operation becomes necessary and essential, to do so face the challenge. supply and demand of agricultural products fresh throughout the year for a strictly increasing population (Gates, R. S.K. Chao and N. Sigrimis, 2001; Didi Faouzi and Nacereddine Bibi Triki, 2016).

We are interested in this product conditioning of agricultural greenhouse while characterizing the dynamic operation of the complex system that is the greenhouse with its various compartments ( $\mathrm{S}$. Bendimerad and T. Mahdjoub, 2014; B. Draoui and F. Bounaama, 2013), develop models to reproduce the essential properties, mechanisms and interactions different compartments and to approach the analysis of thermo-fluid behavior of agricultural greenhouse.

New climate techniques have emerged, including the use of regulation devices ranging from classical to the use of artificial intelligence, such as neural networks and / or fuzzy logic, etc.

Many facilities have been designed to regulate and monitor climate variables in an agricultural greenhouse, such as: Temperature, Humidity, $\mathrm{CO} 2$ concentration, Irrigation, the ventilation, etc. The possibilities offered by greenhouse climate computers have solved the problems relating to the regulation and respect of climate instructions required by protected cultivation (M. El Aoud and M. Maher, 2014).

The climate computer greenhouse will have to be integrated as a tool for dynamic management of production, able to choose the most appropriate climate route, meet objectives and production orders, while minimizing inputs.

The complexity of managing and optimizing this environment can not be addressed only through a comprehensive approach to operating greenhouses-systems (Didi Faouzi and N. Bibi Triki, 2016).

Greenhouse management and the urgent and varied consumer demand make the problem multivariable, nonlinear and highly complex.

\section{Modeling the greenhouse}

This article deals with the modeling and simulation of our greenhouse model which is based on the method of GUESS (Jamisson M. Hill, 2006).

GUESS is a model set in parameter block, meaning that spatial heterogeneity is ignored and it is assumed that the inner content and the flow through the system boundary are evenly distributed.

The conservation equations are used to model the rate of system status change.

$\checkmark$ For a warm greenhouse these state variables would be the indoor temperature, relative humidity, air pressure and $\mathrm{CO} 2$ concentration.

Malika Amari, Didi Faouzi, Benyoucef Khalili, Foudil Benzerafa, Mohammed Salim Hadjidj

Comparative analysis of the management of the results of the modeling and the simulation of the evaluation of the thermal energy of the greenhouse...
ADCAIJ: Advances in Distributed Computing and Artificial Intelligence Journal Regular Issue, Vol. 10 N. 1 (2021), 77-97 eISSN: 2255-2863 - https://adcaij.usal.es Ediciones Universidad de Salamanca - CC BY-NC-ND 
For the plant state variables are the water content, the body temperature, dry weight or biomass, and internally sheet $\mathrm{CO} 2$.

A complete equation for the transport of some scalar quantity through a control volume is as following:

$$
C V \frac{\partial \Phi}{\partial x}=A\left(F_{\text {int }}-F_{\text {out }}\right)+V\left(Q_{\text {source }}-Q_{\text {sink }}\right)
$$

$\mathrm{C}$ : The heat capacity $\left(\mathrm{J} / \mathrm{m}^{3} . \mathrm{k}\right)$

V: System Volume $\left(\mathrm{m}^{3}\right)$

$\Phi:$ is a quantity describing the state of the system $\left(\mathrm{W} / \mathrm{m}^{2}\right)$

$\mathrm{dx}$ : Material thickness (m)

A: The flow boundary surface (control surface) $\left(\mathrm{m}^{2}\right)$

$\mathrm{F}_{\text {int }}, \mathrm{F}_{\text {out }}$ : Internal and external flux $\left(\mathrm{W} / \mathrm{m}^{2}\right)$

\subsection{Modeling the climate of the greenhouse systems}

The greenhouse is a closed system. It exchanges heat with greenhouse microclimate systems such as heating, cooling and ventilation systems. The microclimate system is also a dynamic system in which internal variables interact to produce variations at different spatial and temporal scales. A thorough knowledge of these complex variations constitutes a basis for first understanding the behavior of the climate and then foreseeing its evolution in order to control them. A climate model involves numerically integrating a set of mathematical equations that represent the behavior of the climate system (or subsystem).

\subsubsection{Cooling Pad Model}

In a greenhouse, evaporative cooling devices are used to reduce the temperature when the fan can not reach appropriate levels for optimal plant growth. In equipped greenhouses, cooling evaporation is the second part of the unrealized gain. Most evaporative cooling methods can be modeled as adiabatic cooling process; the minimum temperature and the achievable maximum vapor pressure is equal to the wet bulb.

The effectiveness of the typical tablet is about $85 \%$. The heat loss rate depends on the fan speed.

$$
\begin{aligned}
& H_{\text {pad }}=H_{\text {out }+\eta_{\text {pad }}}\left(H_{w b}-H_{\text {out }}\right) \\
& T_{\text {pad }}=T_{\text {out }-\eta_{\text {pad }}}\left(T_{w b}-T_{\text {out }}\right) \\
& \mathcal{Q}_{\text {pad }}=\rho \dot{V} F a n C_{P} \eta_{\text {pad }}\left(T_{\text {out }}-T_{w b}\right)
\end{aligned}
$$

$\eta_{\text {pad }}:$ Pad efficiency

$\mathrm{T}_{\text {out }}, \mathrm{T}_{w b}$ : The difference between the outside temperature and wet bulb (K)

$C_{p}:$ Specific heat $(\mathrm{J} / \mathrm{kg} . \mathrm{k})$

$\rho$ : Density $\left(\mathrm{kg} / \mathrm{m}^{3}\right)$

$\dot{V}:$ fan speed $(\mathrm{m} / \mathrm{s})$

Malika Amari, Didi Faouzi, Benyoucef Khalili, Foudil Benzerafa, Mohammed Salim Hadjidj

Comparative analysis of the management of the results of the modeling and the simulation of the evaluation of the thermal energy of the greenhouse...
ADCAIJ: Advances in Distributed Computing and Artificial Intelligence Journal Regular Issue, Vol. 10 N. 1 (2021), 77-97 elSSN: 2255-2863 - https://adcaij.usal.es 


\subsubsection{Model of fogging system}

The flow of steam and heat are determined through Ohm's Law and is as following:

$$
\begin{aligned}
& \dot{e}=K A_{\text {net }}\left(V P_{\text {sat }}\left(T_{w b}\left[T_{\text {air }}, r h_{\text {air }}\right]\right)-V P_{\text {air }}\right) \\
& q=\lambda \dot{e}
\end{aligned}
$$

$q$ : Is the heat transfer between the nebulizer and the air of agricultural greenhouse $\left(\mathrm{W} / \mathrm{m}^{2}\right)$.

$\mathrm{K}$ : Global coefficient of heat transmission $\left(\mathrm{W} / \mathrm{m}^{2} \cdot \mathrm{k}\right)$.

$P_{\text {sat }}:$ Saturation pressure (Pascale).

$P_{a i r}:$ Pression de l'air ambiant (pascale)

$\lambda$ : Thermal conductivity $\left(\mathrm{W} / \mathrm{m}^{2} \mathrm{k}\right)$.

\subsubsection{Evaluation of the wall temperature $\mathrm{T}_{\mathrm{p}}$}

The $\mathrm{T}_{\mathrm{p}}$ wall temperature evaluation model, closest to reality is determined based on the average temperatures $T_{p i}$ and $T_{p e}$

$$
T_{p}=\frac{T_{p_{i}}+T_{p_{e}}}{2}
$$

The indoor and outdoor temperatures and are:

$$
\begin{aligned}
& T_{p_{i}}=T_{a i r, i}-\frac{K\left(T_{a i r, i}-T_{a i r, e}\right)}{h_{p_{i}}} \\
& T_{p_{e}}=T_{a i r, e}+\frac{K\left(T_{a i r, i}-T_{a i r, e}\right)}{h_{p_{e}}}
\end{aligned}
$$

The temperature evaluation model of $\mathrm{T}_{\mathrm{p}}$ wall will be expressed:

$$
\begin{gathered}
T_{p}=\frac{T_{a i r, i}+T_{a i r, e}}{2}+\frac{k\left(h_{p_{i}}-h_{p_{e}}\right)}{h_{p_{i}} \cdot h_{p_{e}}} \cdot \frac{T_{a i r, i}-T_{a i r, e}}{2} \\
T_{p}=\frac{T_{a i r, i}+T_{a i r, e}}{2}+C_{B} \frac{T_{a i r, i}-T_{a i r, e}}{2}
\end{gathered}
$$

Where: $\quad C_{B}=\frac{\lambda\left(h_{p_{i}}-h_{p_{e}}\right)}{\lambda\left(h_{p_{i}}+h_{p_{e}}\right)+e h_{p_{i}} h_{p_{e}}}$

$T_{\text {air }, i}, T_{\text {air },}:$ Dry Air temperature Inside / Outside (K)

$h_{\text {air }, i}, T_{\text {aire }}$ : Coefficient of superficial exchanges at the inter wall, of the outer wall $\left(\mathrm{W} / \mathrm{m}^{2} . \mathrm{k}\right)$

$C_{B}$ : Quotient de BIBI(.)

Malika Amari, Didi Faouzi, Benyoucef Khalili, Foudil Benzerafa, Mohammed Salim Hadjidj

Comparative analysis of the management of the results of the modeling and the simulation of the evaluation of the thermal energy of the greenhouse...
ADCAIJ: Advances in Distributed Computing and Artificial Intelligence Journal Regular Issue, Vol. 10 N. 1 (2021), 77-97 eISSN: 2255-2863 - https://adcaij.usal.es Ediciones Universidad de Salamanca - CC BY-NC-ND 
This report dimensionless $C_{B}$ is used in evaluating the wall temperature, it is now called the quotient of BIBI, it is the ratio of the difference of surface thermal exchange by conduction, convection and radiation occurring at the level of the greenhouse coverage.

\subsubsection{Heating system}

The heat produced per unit of fuel is modeled as:

$\underset{\substack{\text { combution } \\ \text { sensible }}}{h_{\text {a }}}=L H V+\lambda \phi *\left[\frac{36}{16} \phi^{-1}-e_{\text {sat }}\left(T_{\text {exhaust }}\right)\right]-(1-r) C_{P, \text { air }} T_{\text {exhaust }}$

$h_{\text {combution }}$

sensible : Sensible heat load of a condensing water heater $(\mathrm{J}), \mathrm{LHV}:$ is lower heating value $(\mathrm{KJ} / \mathrm{kg})$,

$\Phi$ : is the fuel air , 36/16 : is the weight ratio of the produced steam to supply the burner, $T_{\text {exhaust }}:$ is the temperature of the exhaust gas $(\mathrm{k})$ and $\mathrm{r}$ is the return ratio.

\subsection{Energy balance of the greenhouse}

The analytical energy balance equation of the greenhouse:

Stored energy change $=$ Gain from internal sources + Gain from the sun - Losses due to conduction through the cover - Losses due to long wave radiation - Unrealized losses (evaporation) - Losses due to the exchange of air .

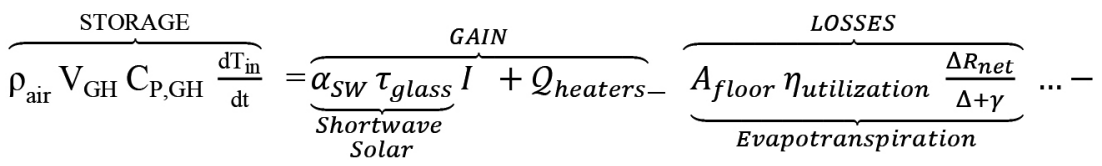

$$
\begin{aligned}
& \ldots-\overbrace{\underbrace{\lambda \mathrm{K}_{\text {net }}\left(V P_{\text {sat }}\left(T_{\text {wb }}\left[T_{\text {air }}, r h_{\text {air }}\right]\right)-V P_{\text {air }}\right)}_{\text {Foggers }}}^{\text {LOSSES CON }} \ldots- \\
& \text { LOSSES CON }
\end{aligned}
$$

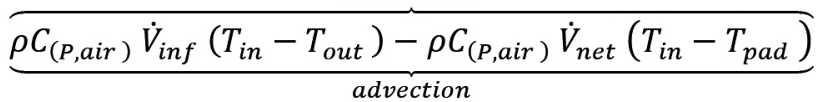

$e_{\text {sat }}$ : Indicates the report saturated with the relative humidity in the sub-model of combustion $(\mathrm{Kg}$ steam / kg air)

$Q_{\text {heaters }}$ : Is the heat provided by the heating system (W)

$r_{\text {conv, in }}, r_{\text {conv,out }}:$ Heat transfer coefficient inside and outside by convection $\left(\mathrm{W} / \mathrm{m}^{2} . \mathrm{k}\right)$

Malika Amari, Didi Faouzi, Benyoucef Khalili, Foudil Benzerafa, Mohammed Salim Hadjidj

Comparative analysis of the management of the results of the modeling and the simulation of the evaluation of the thermal energy of the greenhouse...
ADCAIJ: Advances in Distributed Computing and Artificial Intelligence Journal Regular Issue, Vol. 10 N. 1 (2021), 77-97 eISSN: 2255-2863 - https://adcaij.usal.es 


\subsection{The mass transfer in the greenhouse}

The mass balance for moisture in the greenhouse can be written as following :

$$
\begin{gathered}
\rho_{\text {air }} V_{\text {greenhouse }} \frac{d e_{\text {in }}}{d t}=-\dot{V}_{\text {inf }} * \rho_{\text {air }}\left(H_{\text {in }}-H_{\text {out }}\right)-\dot{V}_{\text {vent }} * \rho_{\text {air }}\left(H_{\text {in }}-H_{\text {pad }}\right)+ \\
\underbrace{\frac{\Delta R_{\text {net }}}{\lambda+\gamma}}_{\text {Evapotranspiration }}-\underbrace{K_{\text {cond }} A_{\text {cover }}\left[V P_{\text {in }}-V P_{\text {sat }}\left(T_{\text {cover }}\right)\right]}_{\text {condensation }}+ \\
\underbrace{K A_{\text {net }}\left(V P_{\text {sat }}\left(T_{\text {wh }}\left[T_{\text {air }} r h_{\text {air }}\right]\right)-V P_{\text {air }}\right)}_{\text {foggers }}+\underbrace{r \phi e_{\text {sat }}\left(T_{\text {exhaust }}\right) \frac{Q_{\text {heat }}}{h_{\text {combustion }}}}_{\text {combustion }}
\end{gathered}
$$

$\dot{V}_{\text {inf }}:$ The speed of air infiltration $(\mathrm{m} / \mathrm{s})$.

$V_{\text {greenhouse }}$ : The total volume of agricultural greenhouse $\left(\mathrm{m}^{3}\right)$.

$H_{\text {in }}, H_{\text {out }}:$ Is the indoor and outdoor humidity $(\mathrm{KJ} / \mathrm{kg})$.

$\dot{V}_{\text {vent }}$ : Ventilation rate $\left(\mathrm{m}^{3}\right.$ air / s).

And for the humidity balance:

Rates of change in absolute humidity = Infiltration + Ventilation * (humidity difference with the outside) + Misting + Cooling + AND - Condensation.

The status of humidity function is:

$$
\frac{d H_{\text {in }}}{d t} \underbrace{=-n V_{p}\left(H_{\text {in }}-H_{\text {sat }}\right)}_{\substack{\text { Ventilation infiltration } \\ \underbrace{}_{\text {vination }}}}+K_{\text {foggers }}\left(V P_{\text {in }}-V P_{\text {sat,wetbulb }}\right)-K_{\text {condensation }}\left(V P-V P_{\text {sat }}\right)+
$$

$$
\underset{\text { Evapotranspiration }}{E}: \text { The amount of heat provided by evapotranspiration (W) }
$$

Mass balance for $\mathrm{CO} 2$ is :

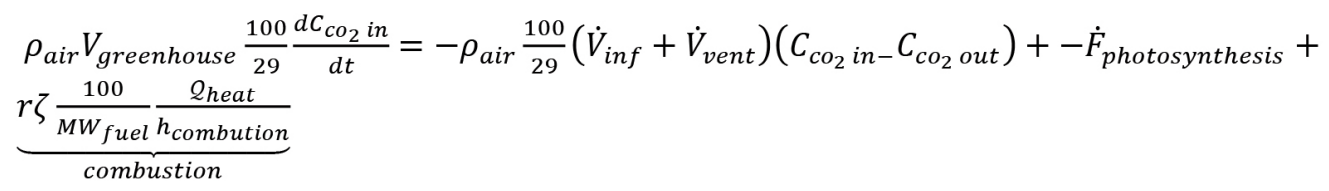


CO2 Mass Balance in molar units (ppm or $\mu \mathrm{mol} \mathrm{CO} 2$ per mol air). $\zeta$ is the number of moles of carbon per mole of fuel.

$\dot{V}_{\text {inf }}$ : Ventilation rate $\left(\mathrm{m}^{3}\right.$ air/s).

$\dot{F}_{\text {photosynthesis }}$ :The amount of heat supplied by photosynthesis (W).

\subsection{Rules of decisions}

$\checkmark$ If (Ti is TVCOLD) then (FOG1FAN1 is OFF)(FOG2FAN2 is OFF)(FOG3FAN3 is OFF)(NV is $\mathrm{OFF})($ Heater1 is $\mathrm{ON})($ Heater2 is $\mathrm{ON})($ Heater3 is $\mathrm{ON})$.

$\checkmark$ If (Ti is TCOLD) then (FOG1FAN1 is OFF)(FOG2FAN2 is OFF)(FOG3FAN3 is OFF)(NV is $\mathrm{OFF})($ Heater1 is $\mathrm{ON})($ Heater2 is $\mathrm{ON})($ Heater3 is OFF).

$\checkmark$ If $(\mathrm{Ti}$ is TCOOL) then (FOG1FAN1 is OFF)(FOG2FAN2 is OFF)(FOG3FAN3 is OFF)(NV is $\mathrm{OFF})($ Heater1 is $\mathrm{ON})($ Heater2 is $\mathrm{OFF})($ Heater3 is OFF).

$\checkmark$ If (Ti is TSH) then (FOG1FAN1 is OFF)(FOG2FAN2 is OFF)(FOG3FAN3 is OFF)(NV is ON) (Heater1 is OFF)(Heater2 is OFF)(Heater3 is OFF).

$\checkmark$ If (Ti is TH) then (FOG1FAN1 is ON)(FOG2FAN2 is OFF)(FOG3FAN3 is OFF)(NV is OFF) (Heater1 is OFF)(Heater2 is OFF)(Heater3 is OFF).

$\checkmark$ If (Ti is TVH) then (FOG1FAN1 is ON)(FOG2FAN2 is ON)(FOG3FAN3 is OFF)(NV is OFF) (Heater1 is OFF)(Heater2 is OFF)(Heater3 is OFF).

$\checkmark$ If (Ti is TEH) then (FOG1FAN1 is ON)(FOG2FAN2 is ON)(FOG3FAN3 is ON)(NV is OFF) (Heater1 is $\mathrm{OFF})($ Heater2 is $\mathrm{OFF})($ Heater3 is $\mathrm{OFF})$.

Where :

$\mathrm{Ti}$ : Indoor temperature.

TVCOLD : Temperature very cold.

TCOLD : Temperature cold.

TCOOL : Temperature is cool.

TSH : Temperature increases slowly.

$\mathrm{TH}$ : Temperature is hot.

TVH : Temperature is very hot.

HE : super hot temperature.

Malika Amari, Didi Faouzi, Benyoucef Khalili, Foudil Benzerafa, Mohammed Salim Hadjidj

Comparative analysis of the management of the results of the modeling and the simulation of the evaluation of the thermal energy of the greenhouse...
ADCAIJ: Advances in Distributed Computing and Artificial Intelligence Journal Regular Issue, Vol. 10 N. 1 (2021), 77-97 eISSN: 2255-2863 - https://adcaij.usal.es Ediciones Universidad de Salamanca - CC BY-NC-ND 
The explanation of the previous decision rules is as follows:

1) If the temperature (TVCOL) inside the greenhouse is very cold, then it is lower than the set temperature, the fuzzy controller sends a signal to automatically trigger all mechanical ventilation and ventilation systems and gives the order of "Open all heating systems".

2) If the temperature (TCOLD) inside the greenhouse is cold , then it is therefore somewhat below the set temperature then the fuzzy controller sends a signal to automatically trigger all mechanical cooling and ventilation systems and gives an order for "Open a single heating system".

3 ) If the temperature inside the greenhouse is cool therefore the controller gives the same previous order.

4) If the temperature (TSH) inside the greenhouse increases slowly, then the controller gives the order to stop all heating, cooling and mechanical ventilation systems and leave the operation of the ventilation natural.

5) If the temperature (TH) inside the greenhouse is hot, then it is slightly higher than the temperature of the set point, then the fuzzy controller sends a signal to automatically trigger all the cooling, heating and ventilation systems and gives Order to "open mechanical ventilation system" (forced).

6) If the temperature (HVT) inside the greenhouse is very hot, it is higher than the set point temperature, the fuzzy controller sends a signal to automatically trigger all heating systems and allow the operation of two mechanical ventilation systems.

7) If the temperature (TEH) inside the greenhouse is super hot, it is therefore superior to the set point temperature. Then the blurred controller sends a signal to automatically open all mechanical cooling and ventilation systems and stop "Operation of heating systems" and natural ventilation mechanical ventilation.

\subsection{Fuzzy sets}

The input variables in a fuzzy control system are generally mapped by sets of membership functions similar to it, called "fuzzy set". The process of converting a crisp input value to a fuzzy value is called "fuzzy logic". A control system may also have different types of switch, or "ON-OFF", inputs and analog inputs and during switching inputs will always be a truth value of 1 or 0 , but the system can handle as simplified fuzzy functions happen to be one value or another. Given "mappings" of input variables membership functions and truth values, the microcontroller then makes decisions for action on the basis of a set of "rules".

A fuzzy controller follows a process that occurs in three successive steps:

- Input fuzzification: transforms the input values into quantities Fuzzy.

- Inference (with rule basis): applies the rules to fuzzed entries In order to make decisions.

Defuzzification: transforms fuzzy decisions into output values determined numerical values.

\section{Simulation and model validation}

Our model is based on the greenhouse GUESS model that is set for a multi greenhouse chapel which each module is $8.5 \mathrm{~m}$ wide, $34 \mathrm{~m}$ deep and ridge height of $4.5 \mathrm{~m}$. Infiltration rate is 1.1 air changes per hour, and a $U$ value of $5.76 \mathrm{~W} / \mathrm{m}^{2} . \mathrm{K}$ was used. The model of the plant was set for Douglas

Malika Amari, Didi Faouzi, Benyoucef Khalili, Foudil Benzerafa, Mohammed Salim Hadjidj

Comparative analysis of the management of the results of the modeling and the simulation of the evaluation of the thermal energy of the greenhouse...
ADCAIJ: Advances in Distributed Computing and Artificial Intelligence Journal Regular Issue, Vol. 10 N. 1 (2021), 77-97 eISSN: 2255-2863 - https://adcaij.usal.es Ediciones Universidad de Salamanca - CC BY-NC-ND 
seedling plants were started at $0.57 \mathrm{~g}$ dry weight, and harvested $1.67 \mathrm{~g}$ dry weight; a new growing season was recorded at harvest.

A set of hourly data for 2015 (1 January to 31 December) weather station of Biskra Algeria [6], was used to validate our model as a CSV file that consists of four columns (global solar radiation, temperature, humidity and wind speed).

The model of the greenhouse was coded using the full version of Windows MATLAB R2012b (8.0.0.783), 64bit (win64) with Simulink. The simulation was performed on a Toshiba laptop. The laptop is equipped with a hard drive $700 \mathrm{~GB}$ and $5 \mathrm{~GB}$ of RAM. Simulink model of the parties were made in "Accelerator" mode that has first generated a compact representation of Code $\mathrm{C}$ of the diagram, then compiled and executed.

\subsection{Membership functions MFs}

A function that specifies the degree to which a given input belongs to a set. The output of a membership function, this value is always limited to between 0 and 1 .

Also known as a membership value or membership grade. Membership functions are used in the Fuzzification and defuzzification steps of a FLS (fuzzy logic system), to map the non-fuzzy input values to fuzzy linguistic terms and vice versa.

In many fuzzy applications, membership functions (MF) have been arbitrarily chosen as trapezoidal, triangular or Gaussian curves depending on the selected ranges.

In our model, the sigmoid membership function is considered to define the input variables and triangular for the output variables.

All membership functions are defined on the normalized domain $[-1,1]$ in the discourse universe. With eight linguistic values, as shown in Fig.1.

This figure illustrates the fuzzy sets of membership functions that contain seven fuzzy sets. The linguistic values of the fuzzy sets used are:

Very cold (TVCOLD), COLD (TCOLD), Uncooked (TCOOL), OK (TGOOD), Low warm (TSH), Warm (TH), Very hot (HST) Designed on the basis of expert knowledge and in specialized literature.

We added to our model of the greenhouse an intelligent regulator using the fuzzy logic and we chose the Mamdani method with a single input, we started by first defining the input data and the outputs, and by The next one tried to link the membership functions in a logical way in order to respond in the following Fig.1.

The following diagrams (Fig.2,3,4) show the Simulink models of heating and cooling and misting systems in our greenhouse :

Malika Amari, Didi Faouzi, Benyoucef Khalili, Foudil Benzerafa, Mohammed Salim Hadjidj

Comparative analysis of the management of the results of the modeling and the simulation of the evaluation of the thermal energy of the greenhouse...
ADCAIJ: Advances in Distributed Computing and Artificial Intelligence Journal Regular Issue, Vol. 10 N. 1 (2021), 77-97 eISSN: 2255-2863 - https://adcaij.usal.es Ediciones Universidad de Salamanca - CC BY-NC-ND 

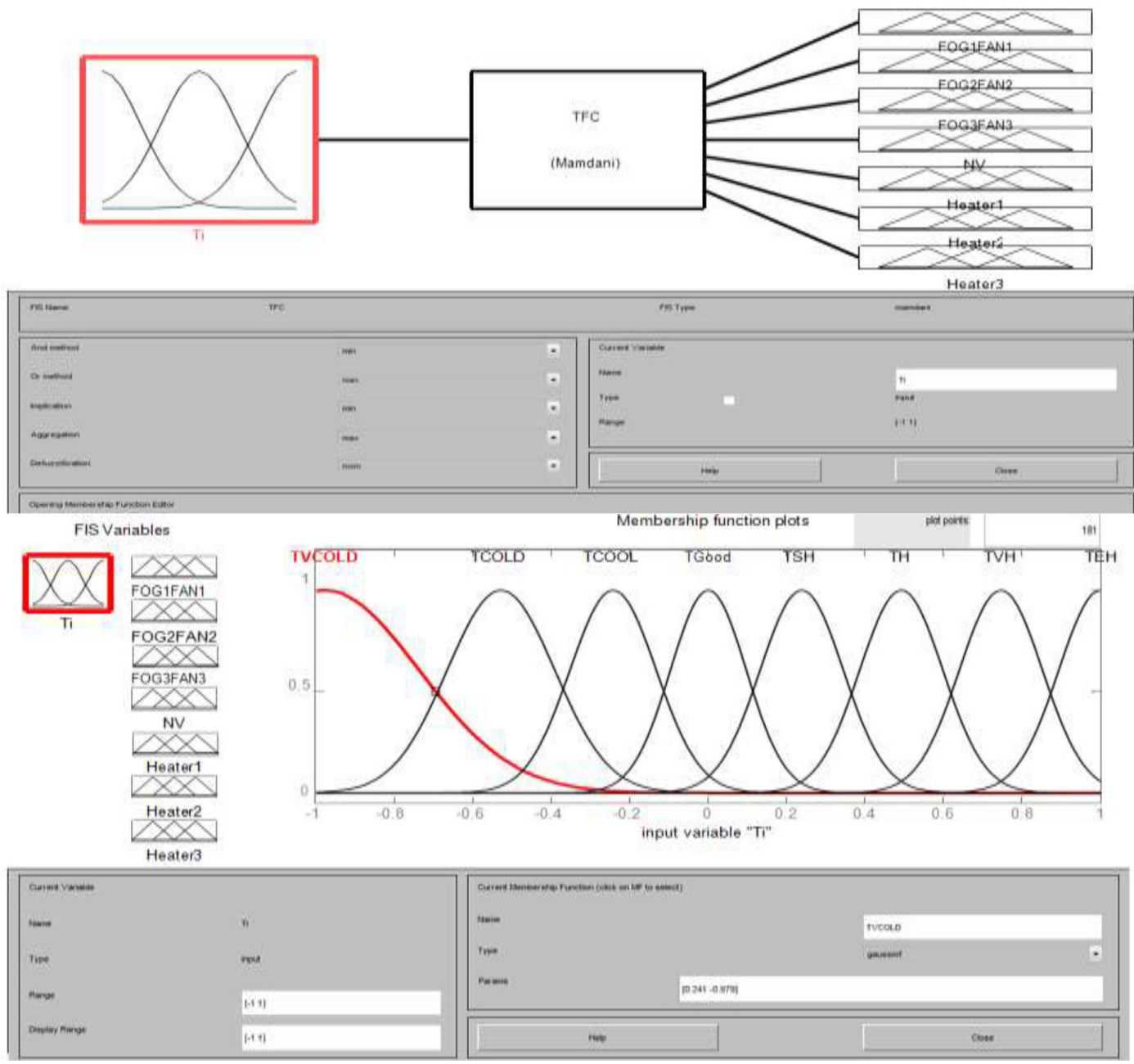

Fig. 1. Representation rules of membership functions

Malika Amari, Didi Faouzi, Benyoucef Khalili, Foudil Benzerafa, Mohammed Salim Hadjidj

Comparative analysis of the management of the results of the modeling and the simulation of the evaluation of the thermal energy of the greenhouse...
ADCAIJ: Advances in Distributed Computing and Artificial Intelligence Journal Regular Issue, Vol. 10 N. 1 (2021), 77-97 eISSN: 2255-2863 - https://adcaij.usal.es Ediciones Universidad de Salamanca - CC BY-NC-ND 


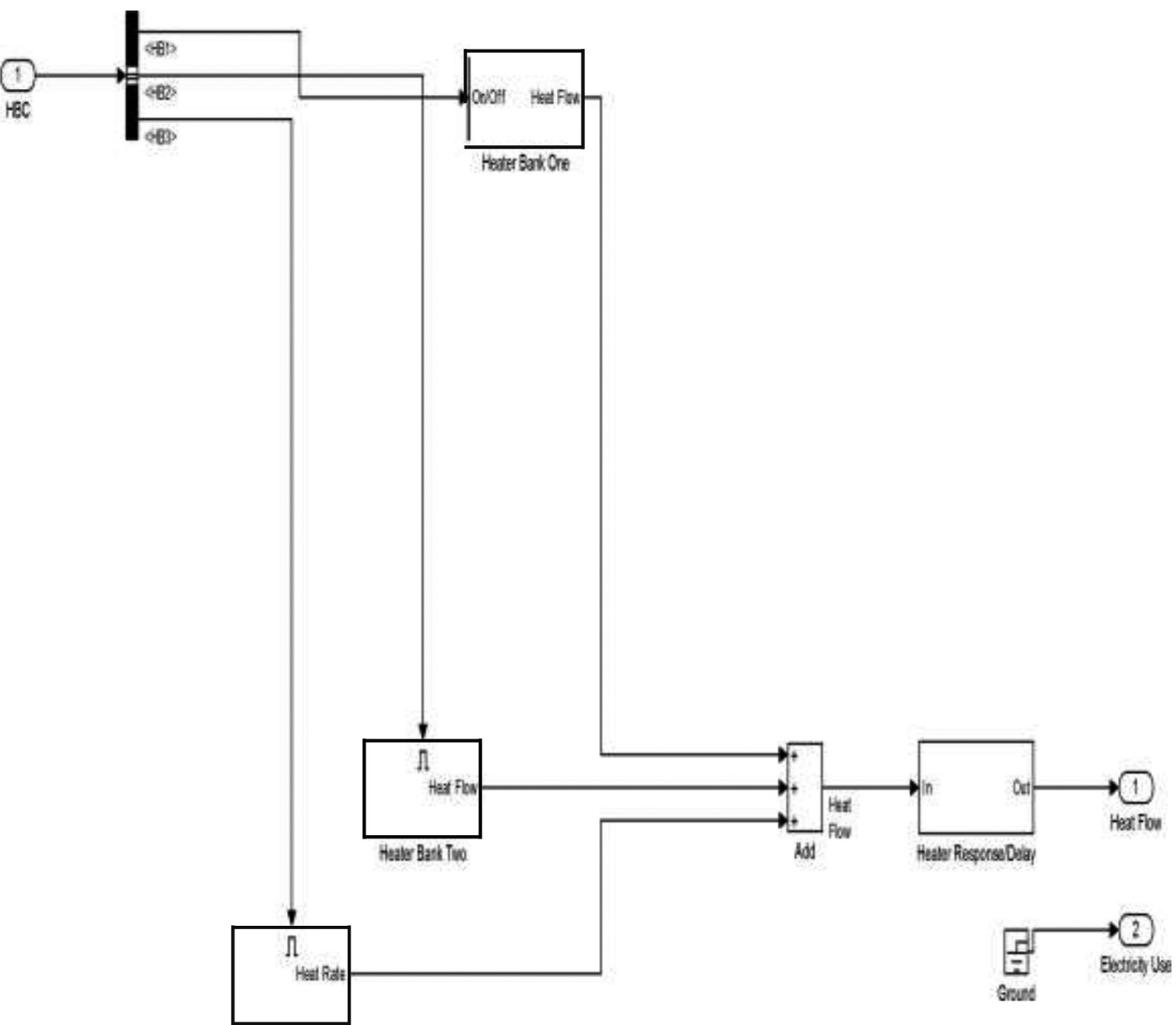

Fig. 2. Simulink representation of the heating system model

Malika Amari, Didi Faouzi, Benyoucef Khalili, Foudil Benzerafa, Mohammed Salim Hadjidj

Comparative analysis of the management of the results of the modeling and the simulation of the evaluation of the thermal energy of the greenhouse...
ADCAIJ: Advances in Distributed Computing and Artificial Intelligence Journal Regular Issue, Vol. 10 N. 1 (2021), 77-97 eISSN: 2255-2863 - https://adcaij.usal.es Ediciones Universidad de Salamanca - CC BY-NC-ND 


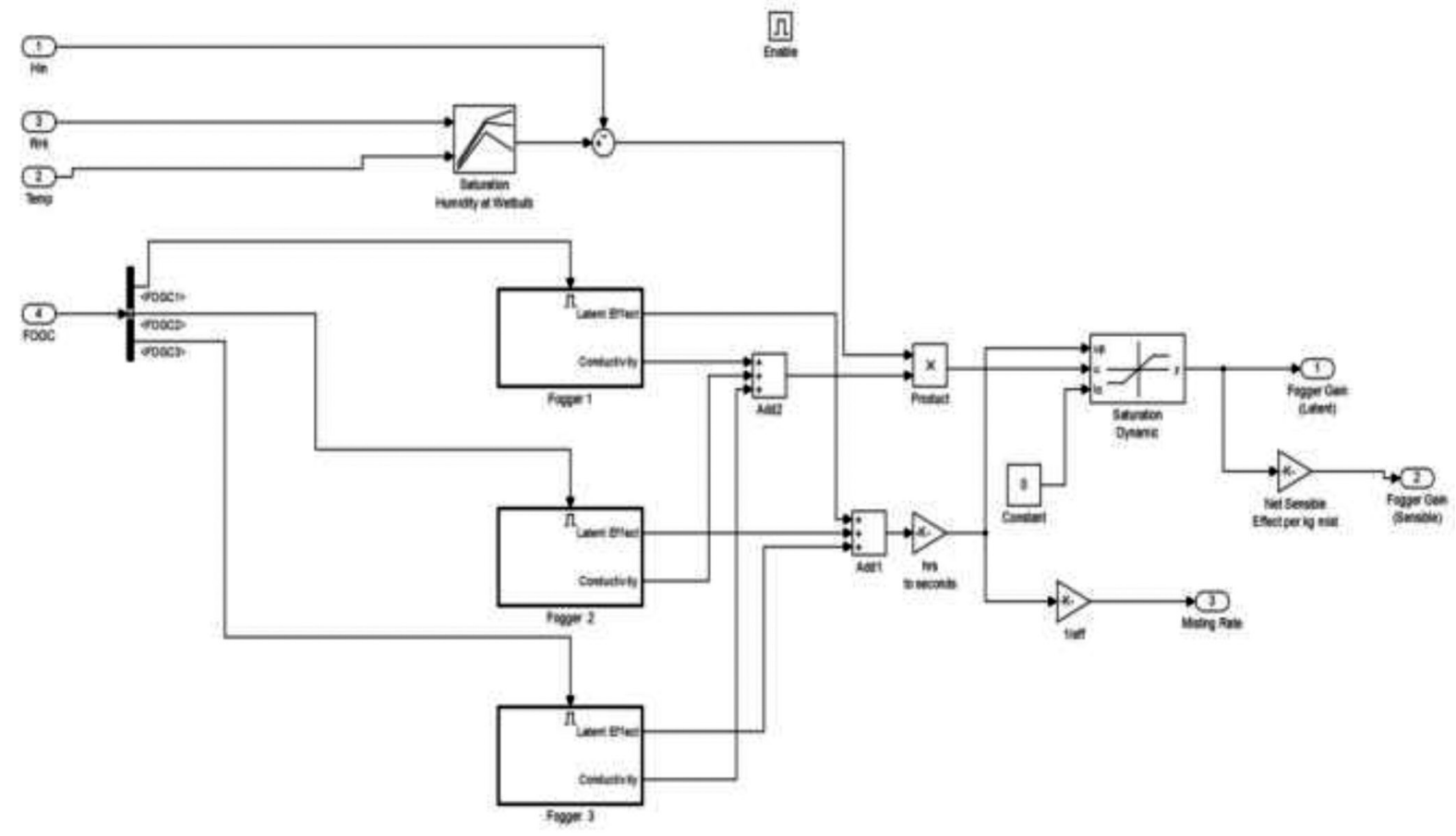

Fig. 3. Simulink representation of the misting system model

Malika Amari, Didi Faouzi, Benyoucef Khalili, Foudil Benzerafa, Mohammed Salim Hadjidj

Comparative analysis of the management of the results of the modeling and the simulation of the evaluation of the thermal energy of the greenhouse...
ADCAIJ: Advances in Distributed Computing and Artificial Intelligence Journal Regular Issue, Vol. 10 N. 1 (2021), 77-97 eISSN: 2255-2863 - https://adcaij.usal.es Ediciones Universidad de Salamanca - CC BY-NC-ND 


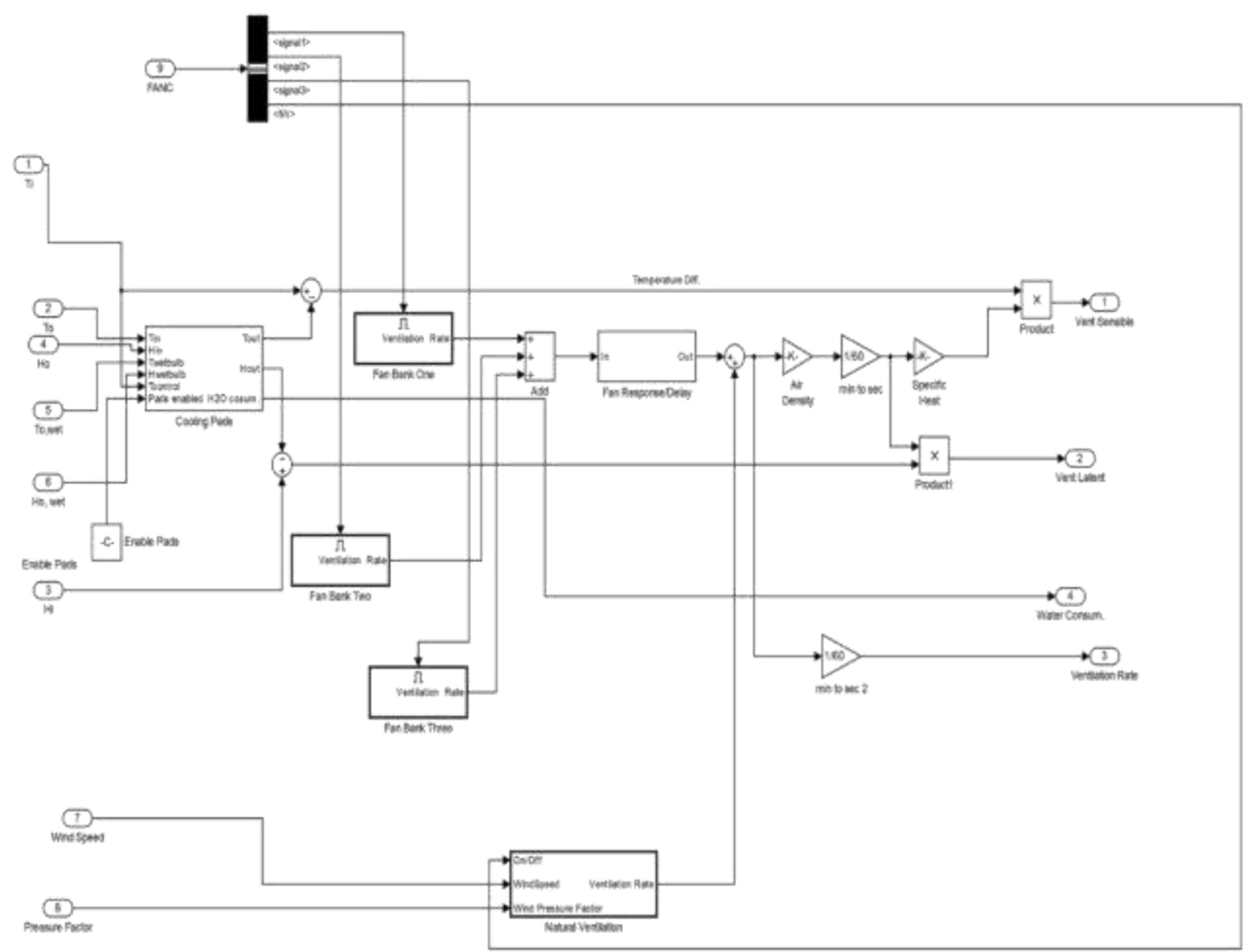

Fig. 4. Simulink Representation of the Ventilation and Cooling Systems

Malika Amari, Didi Faouzi, Benyoucef Khalili, Foudil Benzerafa, Mohammed Salim Hadjidj

Comparative analysis of the management of the results of the modeling and the simulation of the evaluation of the thermal energy of the greenhouse...
ADCAIJ: Advances in Distributed Computing and Artificial Intelligence Journal Regular Issue, Vol. 10 N. 1 (2021), 77-97 eISSN: 2255-2863 - https://adcaij.usal.es Ediciones Universidad de Salamanca - CC BY-NC-ND 


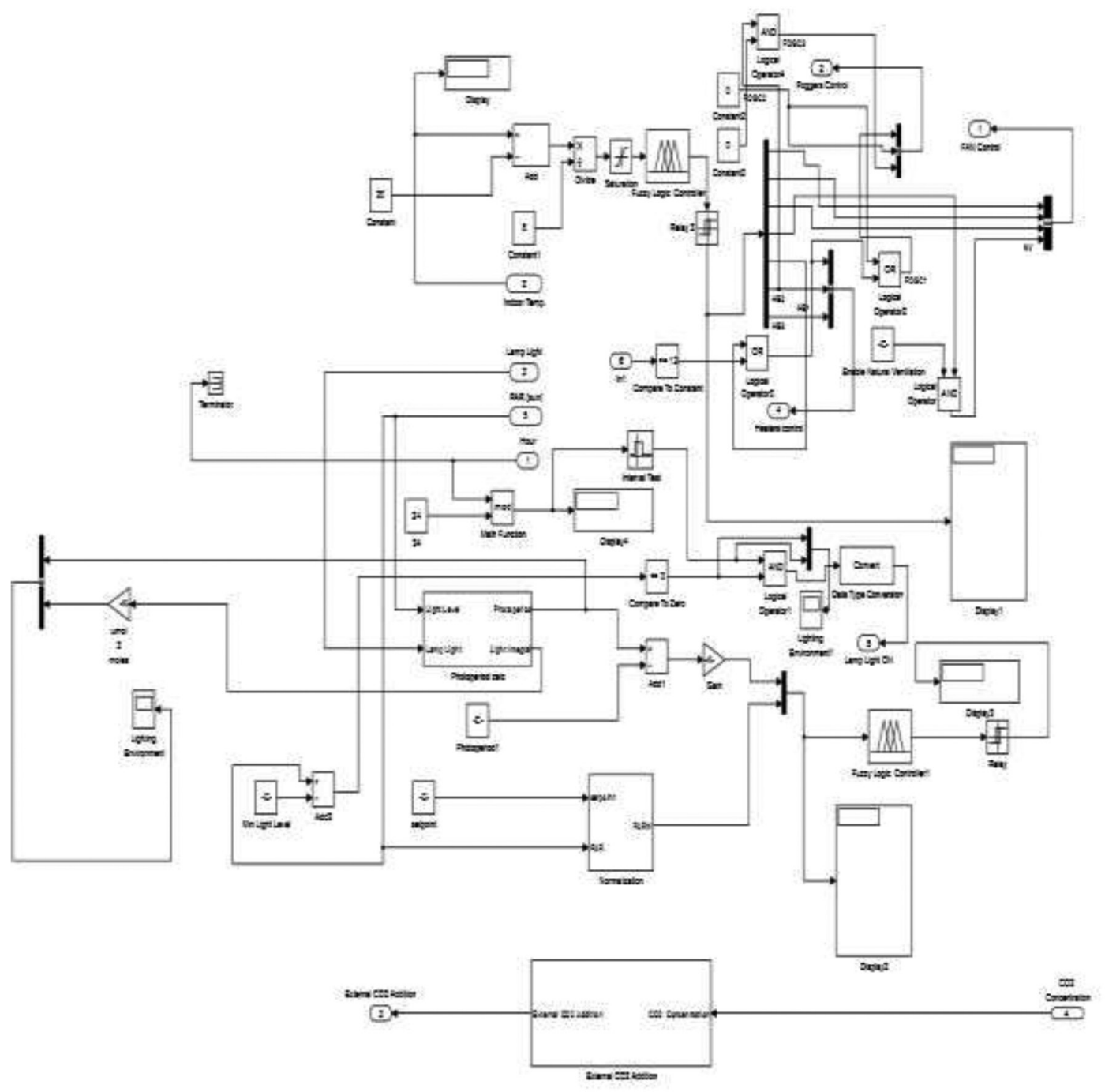

Fig. 5. Fuzzy logic controller simulation model of the greenhouse

\section{$\checkmark$ Discussion of the figures (Fig. 2,3,4,5)}

The simulation of our system was done by MATLAB Simulink. The results of the MATLAB / Simulink software indicate the high capacity of the proposed technique to control the internal temperature of the greenhouse even in the event of a rapid change of atmospheric conditions. The modeling of the system Is defined in the form of this block diagram introduced in our Simulink represented in Fig. 2,3,4 at the top represent Simulink diagrams of our greenhouse microclimate systems such as heating, cooling and ventilating systems in block diagram form (subsystems).

Malika Amari, Didi Faouzi, Benyoucef Khalili, Foudil Benzerafa, Mohammed Salim Hadjidj

Comparative analysis of the management of the results of the modeling and the simulation of the evaluation of the thermal energy of the greenhouse...
ADCAIJ: Advances in Distributed Computing and Artificial Intelligence Journal Regular Issue, Vol. 10 N. 1 (2021), 77-97 eISSN: 2255-2863 - https://adcaij.usal.es Ediciones Universidad de Salamanca - CC BY-NC-ND 
In a block diagram, each machine or block is described by three sets of variables: the inputs, the state variables which describe the condition of the machine, and the output which depend directly upon the state. At each time step, the machine or block can be called upon perform to following commands:

1. Initialize/reset outputs and states

2. Calculate state derivatives

3. Integrate state derivatives to calculate future state

4. Calculate outputs based upon current state

This robust yet simple methodology can be applied to a wide array of processes particularly those involving lumped parameter mass/energy balances or transfer functions, and is thus quite amenable to crop models, which are based on "black box" theory.

The main impetus for using Simulink is that this methodology is built into the structure of the program, allowing the user to focus on the block diagram side of the model.

The fig. 5 represents the Simulink schema of the modeling of our fuzzy controller.

After defining the membership functions, the inference rules have been implemented in such a way as to achieve optimum control as desired, for example if the climate inside the greenhouse becomes lime the regulator will automatically lowering the temperature by closing a heating system or opening a cooling system or by any other means and all this, in order to keep the required instruction which will be translated by the order that is decommissioned in The part (III.1).

We finally save the file (.fix) to load it into the workspace and retrieve it in the Simulink Fuzzy block under the same name of the saved file.

The simulation of our fuzzy controller was done by MATLAB Simulink. The results of the MATLAB / Simulink software indicate the high capacity of the proposed technique to control the internal temperature of the greenhouse even in the event of a rapid change in atmospheric conditions. The modeling of fuzzy controller is defined in the form of this block diagram introduced in our Simulink shown in Figure (IV.5). Which aims to reach the set temperature of $20^{\circ} \mathrm{C}$ required by the internal environment of our greenhouse. Indeed, by varying the ranges of inferences, the efficiency of the regulator has been increased around this set point. It would also be possible to modify the inference rules or the forms of the membership functions used.

\section{Results}

The results of the MATLAB / Simulink software indicate the high capacity of the proposed technique for controlling the climate inside the greenhouse (temperature, humidity) even in the event of a rapid change in atmospheric conditions.

The results of the simulation clearly show the actual thermo-energetic behavior of the agricultural greenhouse, in two different zones, the first is wet for Dar El-Beida Alger and the second is arid for the Biskra willaya (Saharan zone). This allowed us to know the capabilities and performance of our fuzzy controller.

Two databases of the two regions (Biskra and Dar El Beida) were created on a CSV file containing hourly meteorological parameter measurements for the year 2015 (1 January to 31 December) (http:// www.wunderground.com/cgibin/findweather/getForecast?qery²), which are processed on Excel and exported to MATLAB for simulation.

Malika Amari, Didi Faouzi, Benyoucef Khalili, Foudil Benzerafa, Mohammed Salim Hadjidj

Comparative analysis of the management of the results of the modeling and the simulation of the evaluation of the thermal energy of the greenhouse...
ADCAIJ: Advances in Distributed Computing and Artificial Intelligence Journal Regular Issue, Vol. 10 N. 1 (2021), 77-97 eISSN: 2255-2863 - https://adcaij.usal.es Ediciones Universidad de Salamanca - CC BY-NC-ND 
$\checkmark$ Results Simulation for the Wetland Region (Dar EI Beida):

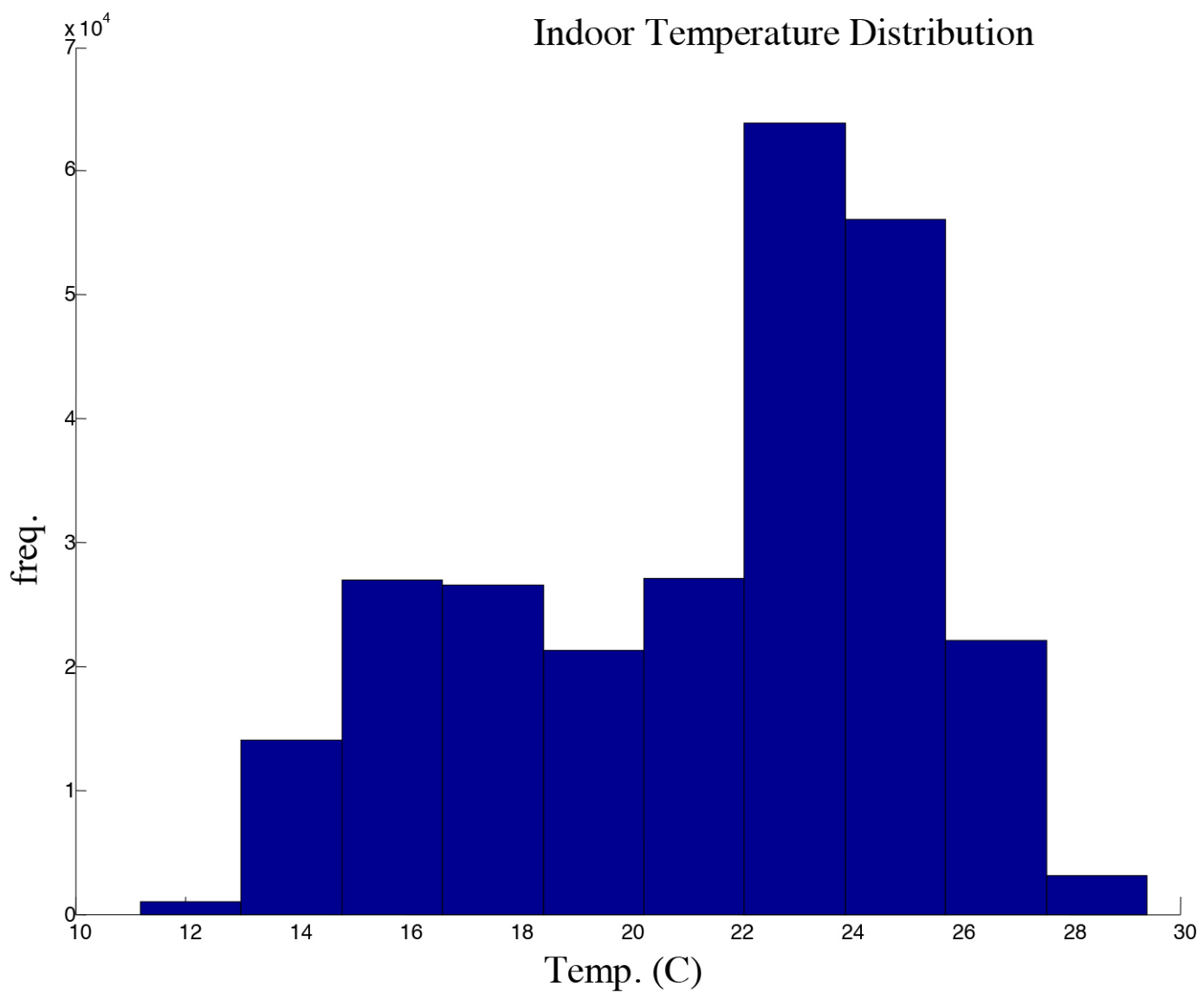

Fig. 6. Histogram shows the distribution of indoor temperature

Malika Amari, Didi Faouzi, Benyoucef Khalili, Foudil Benzerafa, Mohammed Salim Hadjidj

Comparative analysis of the management of the results of the modeling and the simulation of the evaluation of the thermal energy of the greenhouse...
ADCAIJ: Advances in Distributed Computing and Artificial Intelligence Journal Regular Issue, Vol. 10 N. 1 (2021), 77-97 eISSN: 2255-2863 - https://adcaij.usal.es Ediciones Universidad de Salamanca - CC BY-NC-ND 

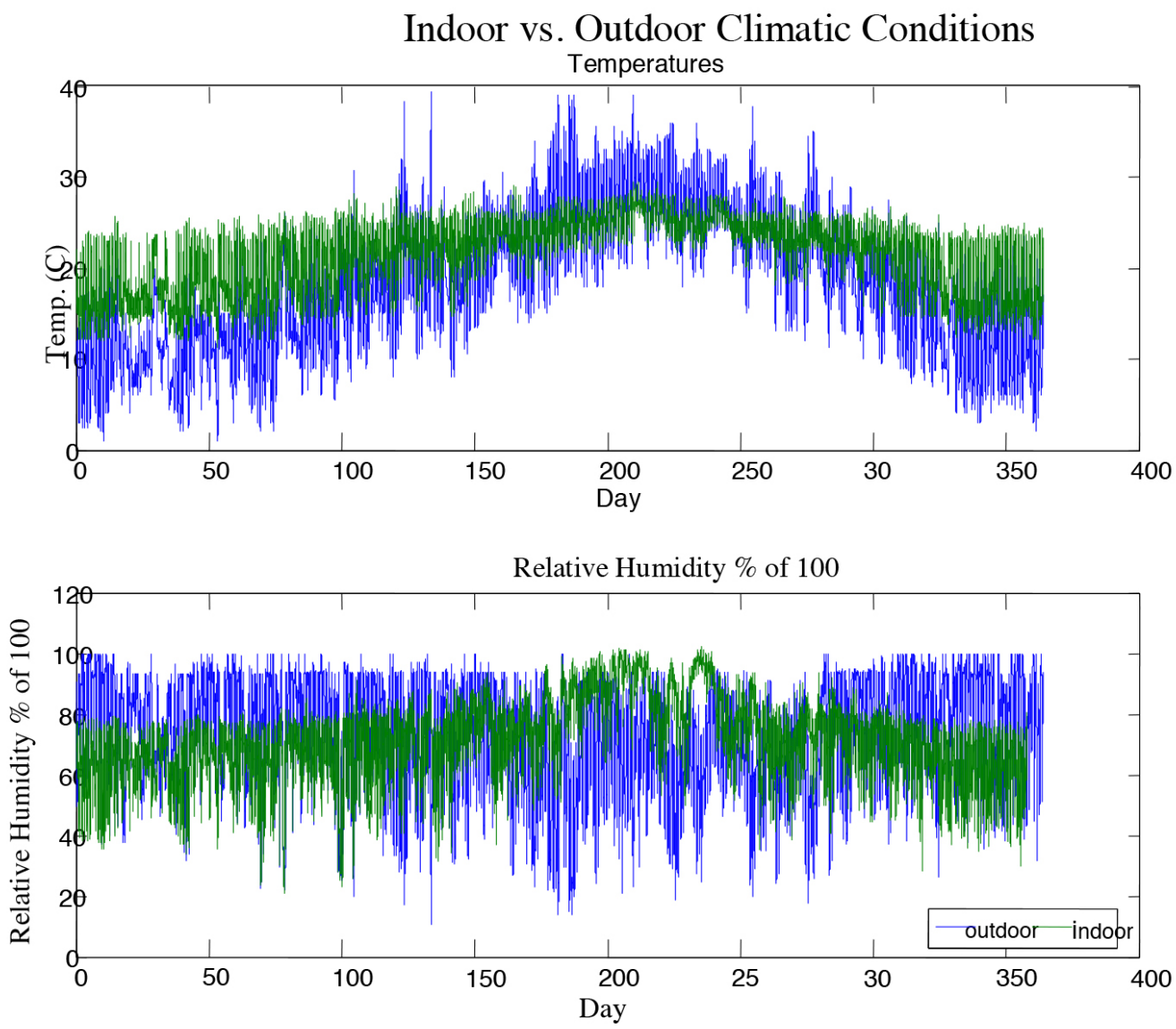

Fig. 7. The evolution of humidity and temperature (interior / exterior)

Malika Amari, Didi Faouzi, Benyoucef Khalili, Foudil Benzerafa, Mohammed Salim Hadjidj

Comparative analysis of the management of the results of the modeling and the simulation of the evaluation of the thermal energy of the greenhouse...
ADCAIJ: Advances in Distributed Computing and Artificial Intelligence Journal Regular Issue, Vol. 10 N. 1 (2021), 77-97 eISSN: 2255-2863 - https://adcaij.usal.es Ediciones Universidad de Salamanca - CC BY-NC-ND 


\section{Results Simulation for the Arid Region (Biskra):}

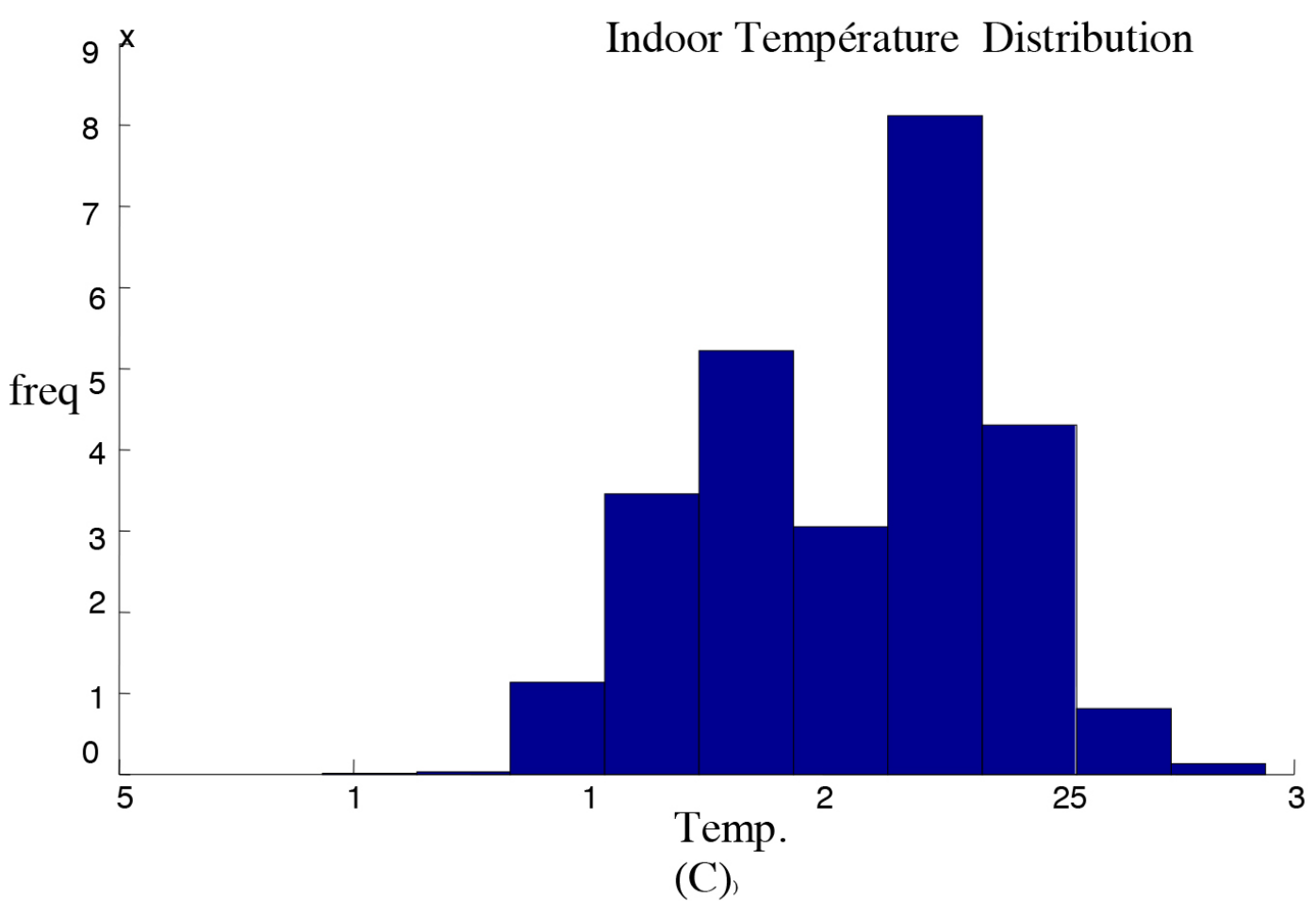

Fig. 8. Histogram shows the distribution of indoor temperature

Malika Amari, Didi Faouzi, Benyoucef Khalili, Foudil Benzerafa, Mohammed Salim Hadjidj

Comparative analysis of the management of the results of the modeling and the simulation of the evaluation of the thermal energy of the greenhouse...
ADCAIJ: Advances in Distributed Computing and Artificial Intelligence Journal Regular Issue, Vol. 10 N. 1 (2021), 77-97 eISSN: 2255-2863 - https://adcaij.usal.es Ediciones Universidad de Salamanca - CC BY-NC-ND 

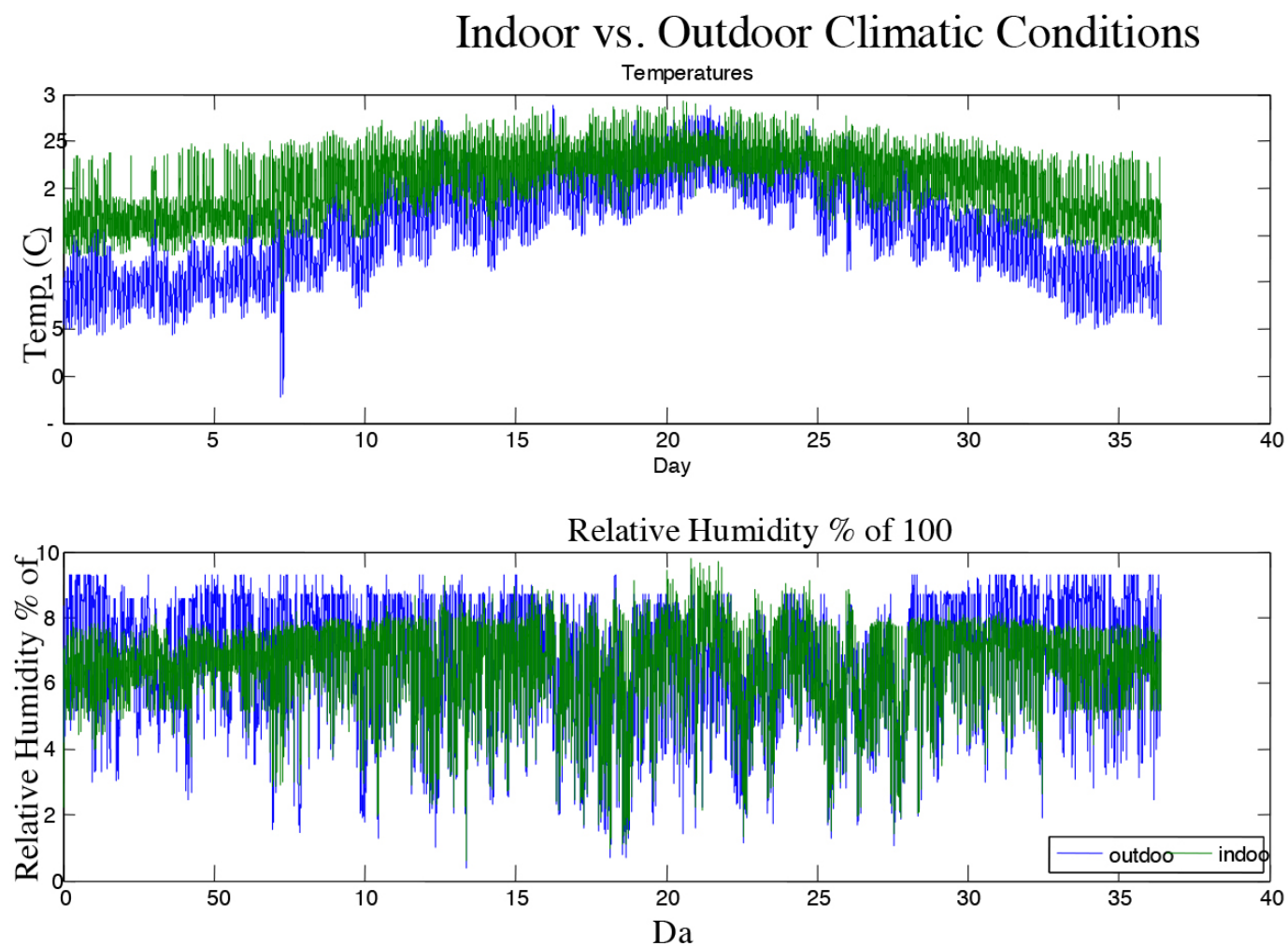

Fig. 9. The Evolution of Humidity and Temperature (Interior / Exterior)

\section{$\checkmark$ Discussions on above figures (Fig. 6, 7, 8, 9):}

It is found that most internal temperature values lie between $\left(15^{\circ} \mathrm{C}\right.$. and $25^{\circ} \mathrm{C}$.) in the figure $(6)$ and between $\left(14^{\circ} \mathrm{C}\right.$. and $22^{\circ} \mathrm{C}$.) in the figures (8) for the winter period and between $\left(20^{\circ} \mathrm{C}\right.$ and 28 ${ }^{\circ} \mathrm{C}$ ) and between $\left(20\right.$ and $\left.26^{\circ} \mathrm{C}\right)$ in the two preceding figures for the spring summer period a large variation in temperature during The autumn and winter period is due to heat loss overnight and the noise occurring in the ambient temperature signal is caused by cyclic activation and deactivation of the heating and ventilation systems. However, the compensation of the heating is insufficient and expensive, for this reason an improved thermal insulation for the wall of the cover is necessary.

The improved thermal insulation of the lid can be practically achieved by the addition of a layer of plastic air bubble mounted on the inner wall face. During the spring summer period the temperature is almost in the desired range in both regions except for the half of the summer where the temperature is a little increase. The use of cooling and spraying systems is necessary to lower the temperature in the desired range. But this solution is insufficient and really costly, for this purpose we should improve the characteristics of the cover of the agricultural greenhouse, double wall thermal insulation that demonstrates improved heating and cooling efficiency, etc.

The relative humidity in the fig. 7, 9 generally remains near the optimum for the whole year except in summer when humidity falls below the threshold due to the significant vaporization used for

Malika Amari, Didi Faouzi, Benyoucef Khalili, Foudil Benzerafa, Mohammed Salim Hadjidj

Comparative analysis of the management of the results of the modeling and the simulation of the evaluation of the thermal energy of the greenhouse...
ADCAIJ: Advances in Distributed Computing and Artificial Intelligence Journal Regular Issue, Vol. 10 N. 1 (2021), 77-97 eISSN: 2255-2863 - https://adcaij.usal.es Ediciones Universidad de Salamanca - CC BY-NC-ND 
temperature compensation. This problem consists of adding a screen on the roof of the greenhouse for the Dar El Beida region and improving irrigation to compensate for the lack of relative humidity in the arid region (Biskra).

The application of our blurred controller can be harvested four times in a year for both regions (humid Dar El Beida and arid Biskra), but at the end of the year to December and beginning of the year to January. It is noted that the operation of the crop or the growth of the plant is a little heavy and take little more time than the other seasons and in both regions.

This negative growth is caused by insufficient integral light during the winter and which means a break in our model and a lowering in light and photoperiod. And this indicates that despite the results obtained in the desired interval, our blurred controller found difficulties for the optimal climate management inside our model of the greenhouse and exactly in the winter period (end of December and beginning of January) and this indicates that our system is unstable in this period.

And it makes us think of its development and improve it in the future to get better results.

\section{Conclusion}

However, our objective is achieved to the extent that it has been shown through modeling and control by the use of fuzzy logic, this area is very difficult because it is a multi control variables which the greenhouse is a biophysical system where parameters are highly correlated as shown by the results. This technique of fuzzy logic that has been adapted to the greenhouse to a promising future for the climate control and management of the greenhouse. For greenhouse growers, it is a preferred approach for structuring and knowledge aggregation and as a means of identification of gaps in the understanding of mechanisms and interactions that occur in the system - greenhouse.

Fuzzy logic is a branch of artificial intelligence, which must point out its advantages and disadvantages. its use has led to quite satisfactory results of the control and regulation perspective.

We remain optimistic in the near future, as to the operation of artificial intelligence, including the use of fuzzy logic which indicates:

$\checkmark$ For the control and regulation of the greenhouse microclimate.

$\checkmark$ By the conservation of energy.

$\checkmark$ For the efficiency of energy use in the greenhouses operation.

$\checkmark$ For improved productivity of crops under greenhouses.

$\checkmark$ In a significant reduction of human intervention.

\section{References}

Jamisson M. Hill, dynamic modeling of tree growth and energy use in a nursery greenhouse using MTLAB and Simulink, Cornell University , 7/31/2006.

Campbell, Neil A.; Brad Williamson; Robin J. Heyden (2006). Biology: Exploring Life (http:/ / www. phschool. com/ el_marketing. html). Boston, Massachusetts: Pearson Prentice Hall. ISBN 0-13250882-6.

Salgado, P., J. B. Cunha, and C. Couto. 1998. A fuzzy identification and controller for the agricultural greenhouse. 7th International Conference on Computers in Agriculture. St. Joseph, MI: ASAE.

Malika Amari, Didi Faouzi, Benyoucef Khalili, Foudil Benzerafa, Mohammed Salim Hadjidj

Comparative analysis of the management of the results of the modeling and the simulation of the evaluation of the thermal energy of the greenhouse...
ADCAIJ: Advances in Distributed Computing and Artificial Intelligence Journal Regular Issue, Vol. 10 N. 1 (2021), 77-97 eISSN: 2255-2863 - https://adcaij.usal.es Ediciones Universidad de Salamanca - CC BY-NC-ND 
S. D. Dhamakale and S.B. Patil, Fuzzy Logic Approach with Microcontroller for Climate Controlling in Green House, International Journal on Emerging Technologies 2(1): 17-19(2011).

N. Bibi-Triki, S. Bendimemerad, A.chermitti, T. Mahdjoub, B. Draoui, A. Abene. Modeling, characterization and Analysis of the dynamic behavior of heat transfer through polyethylene and glass wall of greenhouses . Elsevier -Physics Procedia 21(2011)67-74.

S. Bendimerad, T. Mahdjoub , N. Bibi-Triki , M.z Bessenouci , B. Draoui , H. Brchar, Simulation and Interpretation of the BIBI Ratio CB (.), as a Function of Thermal Parameters of the Low Inertia Polyethylene Wall of Greenhouses. Rev ELSEVIER Physics Procedia 55(2014)157-164.

B. Draoui , F. Bounaama , T. Boulard , N. Bibi-Triki, In-situ Modelization of a Greenhouse Climate Including Sensible Heat, Water Vapor and CO2 Balances. EPD science,2013 EPS Web of conferences 45.01023(2013) DOI : 10105/epjconf/201334501023.

Abdelhafid Hasni , B. Draoui , T. Boulard , Rachid Taibi , Abdedjebar Hezzab, Evolutionary Algorithms in the Optimization of Greenhouse Climate Model Parameters . International Review On Computers and Software (I.RE.CO.S), Vol. 3 , N.6 November 2008.

F. Bouaama , K. Lammari , B. Draoui Greenhouse Air Temperature Control Using Fuzzy PID+I and Neuron Fuzzy Hybrid System Controller International Review of Automatic Control (I.RE.A.CO), Vol. 1. n. 3, pp. 311-320, September 2008.

Abdelhafid Hasni, B. Draoui , T. Boulard, Rachid Taibi , Brahim Dennai, A Particle Swarm Optimization of Natural Ventilation Parameters in a Greenhouse With Continuous Roof Vents Sensor \& Transducers Journal, Vol. 102 , Issue 3 , March 2009 , pp. 84-93.

F. Bouaama, B. Draoui, Greenhouse Environmental Control Using Optimized MIMO PID Technique Sensors \& Transducers Journal, Vol. 133, Issue 10, October 2011, pp. 44-52.

Khelifa Lammari , F. Bouaama, B. Draoui ,Benyoucef Mrah, Mohamed Haidas, GA Optimization of the Coupled Climate model of an order two of a Greenhouse . Rev Elsevier Energy Procedia 18 (2012) $416-425$.

M. Gurbaoui, A. Ed-Dahhak, Y. Elafou, A. Lachhab , L. Belkoura and B. Bouchikhi, Implementation of direct fuzzy controller in greenhouse based on labview, International Journal of Electrical and Electronics Engineering Studies Vol.1 No.1, pp.1-13, September 2013.

Didi Faouzi , Nacereddine Bibi Triki, Ali Chermitti, Optimizing the greenhouse micro-climate management by the introduction of artificial intelligence using fuzzy logic, International Journal of Computer Engineering \& Technology (IJCET), Volume 7, Issue 3, May-June 2016, pp. 78-92, Article ID: IJCET_07_03_007 , Available online http://www.iaeme.com/IJCET/issues. asp?JType $=$ IJCET $\&$ VType $=7 \&$ IType $=3$.

Malika Amari, Didi Faouzi, Benyoucef Khalili, Foudil Benzerafa, Mohammed Salim Hadjidj

Comparative analysis of the management of the results of the modeling and the simulation of the evaluation of the thermal energy of the greenhouse...
ADCAIJ: Advances in Distributed Computing and Artificial Intelligence Journal Regular Issue, Vol. 10 N. 1 (2021), 77-97 eISSN: 2255-2863 - https://adcaij.usal.es Ediciones Universidad de Salamanca - CC BY-NC-ND 